\title{
Controlled Growth and Grafting of High-Density Au Nanoparticles on Zinc Oxide Thin Films by Photo-Deposition
}

Jérémy Cure ${ }^{1, *}$, Hala $\mathrm{Assi}^{2}$, Kévin $\mathrm{Cocq}^{2}$, Lorena Marìn ${ }^{1}$, Katia Fajerwerg ${ }^{2}$, Pierre Fau ${ }^{2}$, Eric Bêche $^{3}$, Yves J. Chabal ${ }^{4}$, Alain Estève ${ }^{1}$, and Carole Rossi ${ }^{1, *}$

${ }^{1}$ LAAS-CNRS, University of Toulouse, 7 avenue du colonel Roche, F-31077 Toulouse, France

${ }^{2}$ LCC-CNRS, University of Toulouse, 205 route de Narbonne, F-31077 Toulouse, France

${ }^{3}$ PROMES-CNRS, 7 rue du Four solaire, 66120 Font Romeu, France

${ }^{4}$ Department of Materials Science \& Engineering, University of Texas at Dallas, Richardson, Texas, United States

Keywords: gold nanoparticle, deposition, photo-deposition, deposition/precipitation with urea

Abstract: The integration of high-purity nano-objects on substrates remains a great challenge for addressing scaling-up issues in nanotechnology. For instance, grafting gold nanoparticles (NPs) on zinc oxide films, a major step process for catalysis or photovoltaic applications, still remains difficult to master. We report a modified photo-deposition (P-D) approach that achieves tight control of the NPs size $(7.5 \pm 3 \mathrm{~nm})$, shape (spherical), purity, and high areal density $\left(3500 \pm 10 \mathrm{NPs} / \mu^{2}\right)$ on $\mathrm{ZnO}$ films. This deposition method is also compatible with large $\mathrm{ZnO}$ surface areas. Combining electronic microscopy and $\mathrm{X}$-ray photoelectron spectroscopy measurements, we demonstrate that growth occurs primarily in confined spaces (between the grains of the $\mathrm{ZnO}$ film), resulting in gold NPs embedded within the $\mathrm{ZnO}$ surface grains thus establishing a unique NPs/surface arrangement. This modified P-D process offers a powerful method to control nanoparticle morphology and areal density and to achieve strong 
$\mathrm{Au}$ interaction with the metal oxide substrate. This work also highlights the key role of $\mathrm{ZnO}$ surface morphology to control the NPs density and their size distribution. Furthermore, we experimentally demonstrated an increase of the $\mathrm{ZnO}$ photocatalytic activity due to high densities of Au NPs, opening applications for the decontamination of water or the photoreduction of water for hydrogen production.

\section{Introduction}

Gold nanoparticles (NPs) discovered by Faraday in 1850s continue to nourish several technological areas, fostering both fundamental and applied research, because they exhibit extraordinary optical, chemical, and biological properties that can be exploited in a variety of applications such as sensors, photocatalysis, photovoltaic devices and biological labelling. ${ }^{1-10}$ Gold NPs synthesis is mostly achieved by reduction of $\mathrm{HAuCl}_{4}$ salts by sodium citrate in aqueous solutions. In addition to its reducing role, citrate also acts as a stabilizing agent, as pointed out by Turkevitch. ${ }^{11,12}$ Although the "Turkevitch" method is simple and produces monodispersed size distributions (ca. $15 \mathrm{~nm}$ ), it is not convenient for applications that require a precise positioning of particles (highly-controlled NPs arrangements), such as biological sensing, ${ }^{13}$ stain gauges ${ }^{14}$ and enhanced photovoltaic conversion. ${ }^{15}$

A number of techniques have been reported to deposit NPs on flat surfaces, as recently summarized. ${ }^{16}$ Deposition methods of colloidal suspensions are largely used as cost-efficient techniques to deposit pre-synthesized NPs on any substrate. ${ }^{17,} 18$ These straightforward methods require prior control of the shape and size of the nanoparticles but often lead to poor and random control of their surface distribution. Other more sophisticated techniques have been proposed in the literature, combining simple deposition methods with control of surface chemistry to better position and graft the NPs. For instance, the functionalization of both substrate and particles can enhance adhesion using specific molecules such as DNA and 
SAMs $;{ }^{19}$ the colloidal lithography is also a powerful nanochemical way for patterning NPs on planar substrates ${ }^{20,21}$ and the use of a polymer template has achieved self-organization of noble metal NPs into patterns organized at the nanoscale. ${ }^{22}$

However, these techniques are usually limited to relatively small substrate areas $\left(<\mathrm{cm}^{2}\right)$ and require long processing times. Therefore, the ability to pattern NPs, with a precise control of their position, on 3D architectures and large surface areas $\left(\right.$ several $\left.\mathrm{cm}^{2}\right)$ still remains a technological challenge for the next generation of multi-functional nanodevices and emerging applications. A relevant example is the development of devices based on local surface plasmon resonance (LSPR) of gold nanoparticles deposited on $\mathrm{TiO}_{2}$ or $\mathrm{ZnO}$ thin films either to enhance the catalytic dissociation of water for $\mathrm{H}_{2}$ generation (so-called water splitting) or more the decontamination of water. ${ }^{3-5}$ Notably, the major scientific and technological issues to produce effective water splitting are linked to the gold nanoparticles integration technology since the size, distribution and density of gold nanoparticles on semiconductor films greatly influence the conversion efficiency of absorbed photons to electron generation. ${ }^{23-25}$ First, the technological requirements include the deposition of NPs on large scale devices (several $\mathrm{cm}^{2}$ ) with a high density coverage and well-controlled size and shape at the nanometer scale, which is not yet achievable. Second, during gold nanoparticles deposition, chemical interactions may occur at the gold/semiconductor interface, which depend on the nature of the liquid phase (including the presence or absence of a stabilizing agent around the particles) and also on the deposition technique and conditions. To optimize the surface catalytic activity, the gold/semiconductor interface has to be properly controlled as any contaminants, such as ligands or ionic species originating from the precursors and stabilizing and/or reductive agents, can dramatically screen the gold plasmon/substrate interaction. ${ }^{26}$ Finally, the attachment of the particles on the substrate should be strong enough (i.e. chemical bonding) to avoid their release into the environment. ${ }^{27}$ 
In this paper, we present a novel one-step method to grow Au NPs $(<10 \mathrm{~nm}$ in diameter $)$ in confined spaces with high density (> $\left.1000 \mathrm{NPs} / \mu \mathrm{m}^{2}\right)$ and excellent uniformity over large area $\mathrm{ZnO}$ films. This method is based on photo-deposition (P-D) and uses citrates as stabilizer instead of polymers as is traditionally done. For completeness and calibration, this method is compared to two other techniques: spin coating and deposition/precipitation with urea.

$\mathrm{ZnO}$ has been chosen for its potential role in water splitting applications, since has a wide bandgap with an energy band structure and optoelectronic properties similar to those of $\mathrm{TiO}_{2}$, but with higher electron mobility and lower crystallization temperature. It is one of the best technologically relevant oxide that can be deposited by a number of different techniques such as pulsed laser deposition, sputtering, and atomic layer deposition (ALD). ${ }^{28}$

The P-D method presented here is a new in-situ method based on UV photo reduction of a $\mathrm{HAuCl}_{4}$ salt solution. The method is inspired by recent work that achieved deposition of $\mathrm{Au}$ NPs (10 nm diameter) on $\mathrm{TiO}_{2}$ nanoforests. ${ }^{15}$ Usually, polymer-like polyvinylpyrrolidone (PVP) or polyvinyl alcohol (PVA) are employed to stabilize large Au NPs (ca. $30 \mathrm{~nm}$ diam.) in homogeneous synthesis. ${ }^{29,30}$ The core of our study is therefore to explore the use of citrate ligands instead of polymers to obtain low dimension NPs $(<10 \mathrm{~nm})$. For comparison, two other techniques are evaluated and results detailed in the Supplementary Information: i. the spin coating (SC) of commercial Au NPs since it is a straightforward method easily scalable, ${ }^{31}$ ii. the deposition/precipitation with urea (DPU) that was initially developed for the synthesis of very small gold NPs ( $3 \mathrm{~nm}$ diam.) on metal oxide powder suspensions ${ }^{32,33}$ and has the advantage not to require additional ligands (polymer, ion...) to stabilize the NPs. ${ }^{34-36}$

For each deposition method, scanning electronic microscopy (SEM), high-resolution transmission electronic microscopy (HRTEM) observations, and X-ray photoelectron spectroscopy (XPS) analyses were performed to quantify, the size, size dispersion, density 
and uniformity of the nanoparticles layer, as well as to highlight the nature of the $\mathrm{Au} / \mathrm{ZnO}$ interface. We demonstrate that P-D performed in the presence of citrate ligands enables the control of the size, shape and density of grafted Au NPs on very thin $\mathrm{ZnO}$ films. This comparative study of the limitations and scalability of these three methods for nanostructured $\mathrm{ZnO}$ surfaces reveals that the modified P-D method leads to a high surface coverage with an original surface/NPs arrangement characterized by spatial intercalation within surface $\mathrm{ZnO}$ grains. In addition, modified P-D process consists in a single deposition step and is compatible with large substrate areas. This method, yielding high coverage of intimately grafted nanoparticles, will be particularly useful for applications where miniaturization is key parameter. It also allows to control the density and size $(<10 \mathrm{~nm})$ of grown Au NPs pointing out the role of surface morphology during nucleation and growth, beyond solely chemical considerations. The intimate grafting and high surface density make it possible to achieve measurable photo-reduction of water molecules and demonstrate photo-degradation of Rhodamine $6 \mathrm{G}$ (model of a water pollutant), thus establishing a direct correlation between the grafted-Au NPs density and $\mathrm{ZnO}$ photocatalytic yield. Altogether, these results open to new potential application of $\mathrm{Au} \mathrm{NPs} / \mathrm{ZnO}$ layers obtained by photo-deposition of Au NPs on thin $\mathrm{ZnO}$ surfaces for solar photocatalytic production of hydrogen or water purification.

\section{Materials and Methods}

ZnO surface. The silicon substrates were cleaned by an $\mathrm{O}_{2}$ plasma (800 Watts, 5 min) prior to use. A $25 \mathrm{~nm}$-thick $\mathrm{ZnO}$ film was deposited on this clean silicon substrate by ALD in a Fiji reactor (Nanotech) at $150^{\circ} \mathrm{C}$, using diethylzinc (DEZ) and water vapor as the zinc and oxygen precursors, respectively. The process pressure was set at $\sim 30$ mTorr and the $\mathrm{N}_{2}$ purging gas flow rate was $100 \mathrm{sccm}$, with respective pulse times of $0.02 \mathrm{~s}$ for diethylzinc, $0.01 \mathrm{~s}$ for water, and $20 \mathrm{~s} \mathrm{~N}_{2}$ purge for a total of 175 cycles. Then, the oxidized $\mathrm{Si} / \mathrm{ZnO}$ 
samples were diced into squares $\left(1 \times 1 \mathrm{~cm}^{2}\right)$ and cleaned using $\mathrm{O}_{2}$ plasma (400 Watts, $5 \mathrm{~min}$ ) prior to use.

Deposition of commercial gold nanoparticles. An aqueous colloidal solution $\left(9.73 .10^{10}\right.$ Au NPs.mL ${ }^{-1}$ ) was made from commercial gold nanoparticles (Strem Chemicals) of $8.2 \pm 0.9$ $\mathrm{nm}$ in diameter and stabilized by citrate ligands. See Transmission Electronic Microscopy (TEM) and Dynamic Light Scattering (DLS) characterization in the Supplementary Information file, Figure S9 and Table S1.

Spin coating process. $50 \mu \mathrm{L}$ of the Au NPs solution was first deposited on the $\mathrm{Si} / \mathrm{ZnO}$ samples followed by two consecutive spin coating steps: $500 \mathrm{rpm}$, acc. $500,5 \mathrm{~s}$ and 2000 or 4000 or $6000 \mathrm{rpm}$, acc. 500, 2 min, respectively.

\section{Synthesis and deposition of gold nanoparticles}

Deposition/precipitation with urea process. $\mathrm{Si} / \mathrm{ZnO}$ sample was immersed into $4 \mathrm{~mL}$ of deionized (DI) water in a closed little bottle. $5 \mathrm{~mL}$ of urea solution ([urea] $=5.10^{-2} \mathrm{~mol} . \mathrm{L}^{-1}$ ) and $1 \mathrm{~mL}$ of a $\mathrm{HAuCl}_{4}$ solution $\left(\left[\mathrm{Au}^{3+}\right]=3 \cdot 10^{-3}\right.$ mol. $\left.\mathrm{L}^{-1}\right)$ were added in the bottle at room temperature and under the exclusion of light. The resulting solution was heated at $80{ }^{\circ} \mathrm{C}$ under exclusion of light during $16 \mathrm{~h}$. The substrate was then rinsed in $50 \mathrm{~mL}$ of DI water and dried vertically under ambient temperature and atmospheric pressure. Then, the substrate was dried under vacuum (10 mTorr) during $4 \mathrm{~h}$. Annealing was performed under a reductive and constant flow of an $\operatorname{Ar}(90 \%) / \mathrm{H}_{2}(10 \%)$ mixture $\left(1 \mathrm{~L} \cdot \mathrm{min}^{-1}\right)$ at $300{ }^{\circ} \mathrm{C}$ for $2 \mathrm{~h}$. The increase in temperature was established at $2^{\circ} \mathrm{C} / \mathrm{min}$ and the decrease in temperature by the natural temperature decrease. No additional annealing was therefore performed to enhance NPs chemical attachment.

Photo-deposition process. A $\mathrm{HAuCl}_{4}$ aqueous solution was prepared in the dark by the addition of $\mathrm{HAuCl}_{4}\left(5 \mathrm{mg}, 393.83 \mathrm{~g} \cdot \mathrm{mol}^{-1},\left[\mathrm{Au}^{3+}\right]=2.5 .10^{-4} \mathrm{~mol} \cdot \mathrm{L}^{-1}\right)$ and DI water in a gauged flask of $50 \mathrm{~mL}$. A volume of $5 \mathrm{~mL}$ of this $\mathrm{HAuCl}_{4}$ solution, $0.5 \mathrm{~mL}$ of a solution of 
citrate $\left([\right.$ citrate $]=0.05 \mathrm{~mol} . \mathrm{L}^{-1}$, ratio $[$ citrate $\left.] /\left[\mathrm{Au}^{3+}\right]=20\right)$ and $0.5 \mathrm{~mL}$ of methanol were introduced into a beaker. Then, the $\mathrm{ZnO}-\mathrm{ALD} / \mathrm{Si}$ substrate was immersed into the resulting solution and was irradiated by a UV lamp (100 Watts) for 30 minutes. The grafting of the resulting deposited Au NPs was performed by annealing at $200^{\circ} \mathrm{C}$ during 30 min under ambient air at atmospheric pressure.

\section{Photocatalytic experiments}

Photocatalytic decomposition of Rhodamine 6G. Au NPs/ZnO samples $\left(1 \mathrm{~cm}^{2}\right)$ were immersed in an aqueous solution of Rhodamine $6 \mathrm{G}$ dye $\left(6 \mathrm{~mL}, 5.10^{-6} \mathrm{~mol} . \mathrm{L}^{-1)}\right.$. The solution was kept in the dark for 20 minutes to establish adsorption-desorption equilibrium of the dye, before UV-visible irradiation by UV Rayonet ${ }^{\circledR}$ system (composed of 16 lamps: $\lambda=253.7 \mathrm{~nm}$ (4 lamps), $300 \mathrm{~nm}$ (4 lamps), $350 \mathrm{~nm}$ (4 lamps) and $575 \mathrm{~nm}$ (4 lamps), 224 Watts). During the irradiation, $2 \mathrm{~mL}$ of the solution was removed at given intervals and analyzed using an Agilent Cary 5000 UV-vis spectrometer. After each measurement, the solution was reintroduced to pursue the UV irradiation. In doing so, the loss of the parental solution is minimized. The dye degradation was monitored by measuring the decrease of the dye absorbance at $527 \mathrm{~nm}$ in comparison to the reference point (absorbance value obtained before irradiation).

Photocatalytic production of hydrogen from water-ethanol (50-50) mixture. Au NPs/ZnO samples $\left(1 \mathrm{~cm}^{2}\right)$ were immersed in a 50-50 vol:vol deionized water - ethanol solution $(20 \mathrm{~mL})$ in a quartz reactor. The solution was UV-visible irradiated with a solar simulator (Xenon lamp, 300 Watts) during $48 \mathrm{~h}$ and the hydrogen production was measured by a Perking-Elmer Clarus 580 gas chromatograph (GC) (PlotQ column (30 m) and PE-molisieve column (30 m)), TCD, vector gas: argon).

Characterization. A Zetasizer Nano ZS instrument (Malvern Instruments) was used to determine the nanoparticle hydrodynamic diameters. SEM was performed using a FEI Helios 
600i Nanolab. High Resolution Transmission Electronic Microscopy (HRTEM) and Scanning Transmission Electronic Microscopy - Energy Dispersive X-Ray Spectrometry (STEM-EDS) experiments were carried out in cross-section samples prepared by Focused-Ion Beam (FIB) process in a FEI Helios Nanolab. Lamellas were observed on a JEM-ARM200F cold FEG with a corrected probe field emission at $200 \mathrm{kV}$ with a resolution of $0.19 \mathrm{~nm}$. TEM was performed using a Hitachi 7700 transmission electron microscope operating at $120 \mathrm{kV}$ with a spatial resolution of $2.04 \AA$. Crystalline phases were detected using a Grazing Incidence XRay Diffraction (Bruker D8 Discover system) with a Cu k-alpha radiation as the source. For GI-XRD, the grazing angle was fixed to $1.2^{\circ}$ and two-theta collection angle was ranged from $20^{\circ}$ to $80^{\circ}$ with a step of $0.05^{\circ}$ and a dwell time of $0.1 \mathrm{~s}$ per point. For GI-XRR, the grazing angle was fixed to $1.2^{\circ}$ and two theta-omega collection angles was ranged from $0.4^{\circ}$ to $3.0^{\circ}$ with a $0.005^{\circ}$ step and a dwell time of $0.1 \mathrm{~s}$ per point in all cases. X-ray photoelectron spectroscopy (XPS) (Thermoelectron Kalpha device) with a monochromatized Al-Ka radiation $(\mathrm{h} v=1486.6 \mathrm{eV})$ was used to examine chemical states of the interface after deposition of $\mathrm{Au}$ and $\mathrm{ZnO}$. The pass energy was fixed at $40 \mathrm{eV}$. The spectrometer energy calibration was performed using the $\mathrm{Au} 4 \mathrm{f}_{7 / 2}(83.9 \pm 0.1 \mathrm{eV})$ and $\mathrm{Cu} 2 \mathrm{p}_{3 / 2}(932.8 \pm 0.1 \mathrm{eV})$ core levels. The XPS spectra were recorded in direct mode $\mathrm{N}(\mathrm{Ec})$. The background signal was removed using the Shirley method. ${ }^{37}$ The photoelectron peaks were analysed by Gaussian/Lorentzian $(\mathrm{G} / \mathrm{L}=50)$ peak fitting process.

\section{Results and Discussion}

Characterization of the initial $\mathrm{ZnO}$ film. $\mathrm{ZnO}$ films are notoriously rough, defective, with textured thin film structures generated by columnar growth. We therefore examined the morphology and composition of our ALD-grown $\mathrm{ZnO}$ films by combining SEM, X-ray diffraction (XRD) and XPS. The SEM images obtained after deposition (see image in 
Supplementary Information file Figure S1) indicate that even with ALD, the growth of $\mathrm{ZnO}$ film remains columnar in nature. Over an observation of 500 grains, $67 \%$ of them exhibit an isotropic shape with an average size of $9.2 \pm 0.4 \mathrm{~nm}$ and $33 \%$ present a bean shape with an average size of $15.4 \pm 2 \mathrm{~nm}$. The polycrystalline nature (Wurtzite type) of the film is unraveled by XRD. ZnO peaks are labeled by the corresponding crystallographic axes. The large width of the diffraction spots is consistent with a very thin film. XPS measurements confirm that the $\mathrm{ZnO}$ is stoichiometric, with binding energies of the $\mathrm{Zn} 2 \mathrm{p}_{1 / 2,3 / 2}, \mathrm{Zn} 3 \mathrm{p}_{1 / 2,3 / 2}$ and $\mathrm{O} 1 \mathrm{~s}$ core levels at $1045.4 \pm 0.1 \mathrm{eV}$ and $1022.3 \pm 0.1 \mathrm{eV}, 91.9 \pm 0.1 \mathrm{eV}$ and $89.1 \pm 0.1$ $\mathrm{eV}$ and $530.8 \pm 0.1 \mathrm{eV}$, respectively (Figure S1 c in Supplementary Information file). ${ }^{32}$ Altogether, the above measurements indicate that the $\mathrm{ZnO}$ films are of similar quality to films previously reported in the literature. ${ }^{38}$ 

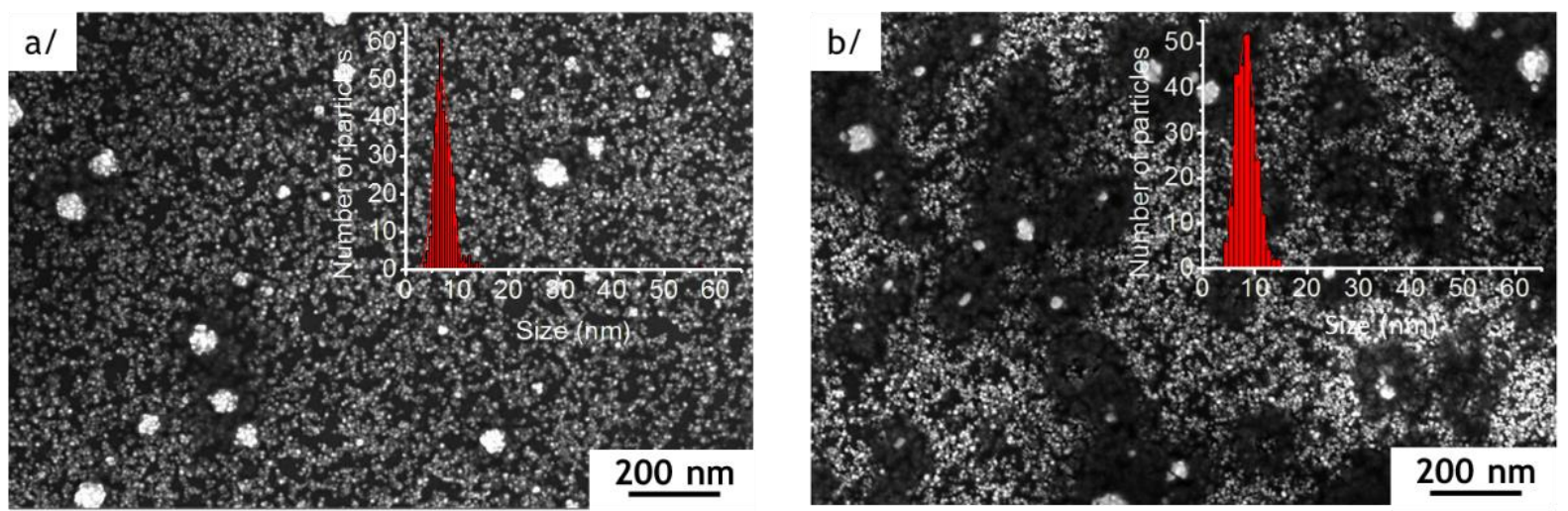

c/

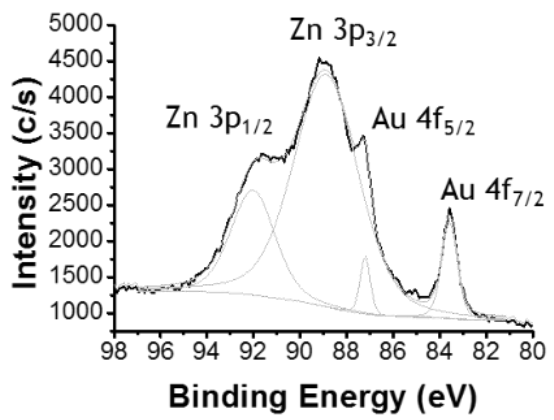

d/
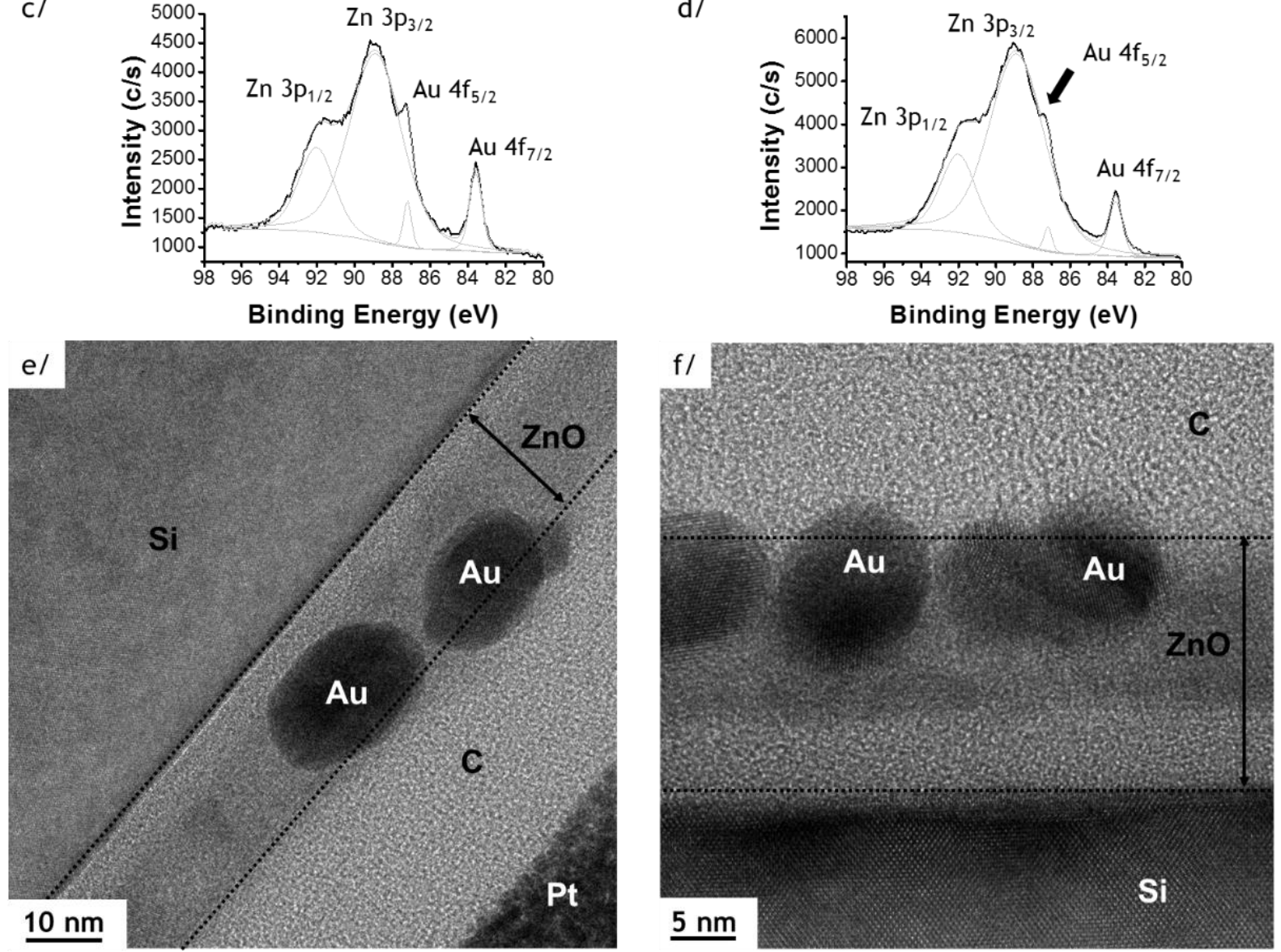

Figure 1. SEM images of $\mathrm{Au}$ NPs deposited on $25 \mathrm{~nm}$ thick $\mathrm{ZnO}$ film by photo-deposition process (with insert showing the size distribution of Au NPs) (a) and (b); XPS spectra of the $\mathrm{Zn} 3 \mathrm{p}_{1 / 2,3 / 2}-\mathrm{Au} 4 \mathrm{f}_{5 / 2,7 / 2}$ region (c) and (d); HRTEM observations (e) and (f); respectively before (sample $\mathrm{Au} / \mathrm{ZnO} 25$, left column) and after the annealing (sample $\mathrm{Au} / \mathrm{ZnO} 25$ 200 ${ }^{\circ} \mathrm{C}$, right column). 
Au NPs photo-deposition (P-D). After the P-D process, SEM observations show a large amount of spherical Au NPs, organized in chain structures (Figure 1, sample Au/ZnO25). The average diameter is $7.5 \pm 3 \mathrm{~nm}$ and the NPs areal density reaches $3500 \pm 10 \mathrm{NPs} / \mu \mathrm{m}^{2}$ (Figure 1 a and Figure S2 in supplementary section). However, after rinsing the NPs on the substrate with DI water (50 $\mathrm{mL}$ by $\mathrm{cm}^{2}$ ), almost all NPs disappear from the surface with a decrease of the NPs areal density to $18 \pm 3 \mathrm{NPs} / \mu \mathrm{m}^{2}$, which indicates their poor adhesion (Figure 2 a). To enhance the grafting, the sample is therefore annealed at $200{ }^{\circ} \mathrm{C}$ during 30 min under air (sample $\mathrm{Au} / \mathrm{ZnO} 25 \_200^{\circ} \mathrm{C}$ ), leading to a slight evolution of the average size of the Au NPs from $7.5 \pm 3 \mathrm{~nm}$ to $8.3 \pm 2 \mathrm{~nm}$ and a slight increase of the NP density $(3700 \pm 10$ $\mathrm{NPs} / \mu^{2}$ ) (Figure $1 \mathrm{~b}$ ). Importantly, SEM pictures show that a few Au NPs touch after the annealing step, which probably results from a dynamic rearrangement of the $\mathrm{Au}$ atoms during annealing.

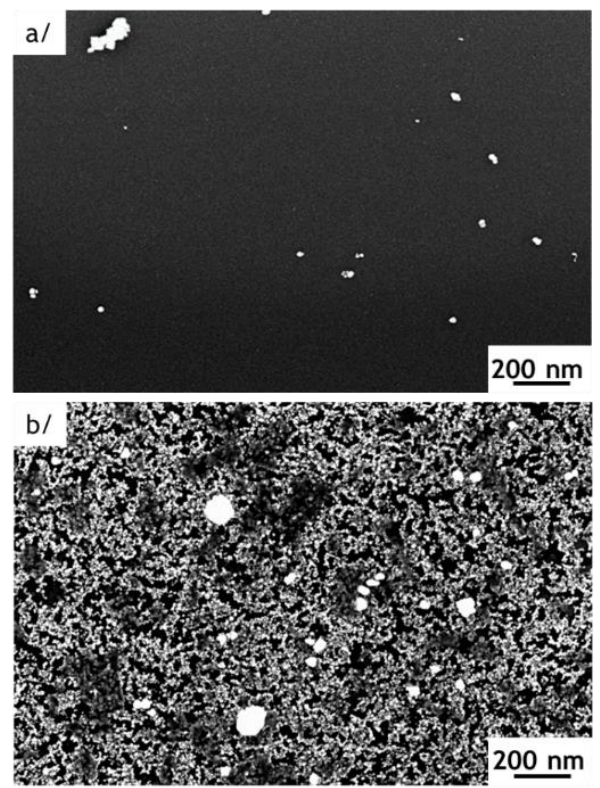

Figure 2. SEM observations of $\mathrm{Au}$ NPs deposited on the $\mathrm{ZnO}$ thin film resulting from the photo-deposition process after the rinsing step of sample $\mathrm{Au} / \mathrm{ZnO} 25$ (a); and sample $\mathrm{Au} / \mathrm{ZnO} 25 \_200^{\circ} \mathrm{C}(\mathrm{b})$. 
The XPS analyses of the binding energies $\mathrm{Zn} 3 \mathrm{p}$ performed on samples before $(\mathrm{Au} / \mathrm{ZnO} 25)$ and after annealing $\left(\mathrm{Au} / \mathrm{ZnO} 25 \_200^{\circ} \mathrm{C}\right)$ are reported in Figure $1 \mathrm{c}$ and Figure $1 \mathrm{~d}$. Four $\mathrm{Zn}$ $3 p_{1 / 2,3 / 2}-A u 4 f_{5 / 2,7 / 2}$ peaks are evidenced (Figure $1 \mathrm{c}, \mathrm{d}$ ) with binding energies located at 92.0 $\pm 0.1 \mathrm{eV}, 88.9 \pm 0.1 \mathrm{eV}, 87.2 \pm 0.1 \mathrm{eV}, 83.6 \pm 0.1 \mathrm{eV}$ and $92.0 \pm 0.1 \mathrm{eV}, 88.9 \pm 0.1 \mathrm{eV}, 87.2 \pm$ $0.1 \mathrm{eV}, 83.6 \pm 0.1 \mathrm{eV}$. The first two peaks correspond to $\mathrm{Zn} 3 \mathrm{p}_{3 / 2}$ and $\mathrm{Zn} 3 \mathrm{p}_{1 / 2}$ (also present on $\mathrm{ZnO}$ thin film after deposition) whereas the two additional peaks correspond to the binding energies of the $\mathrm{Au} 4 \mathrm{f}_{5 / 2,7 / 2}\left(\mathrm{Au} 4 \mathrm{f}_{5 / 2}\right.$ and $\left.\mathrm{Au} 4 \mathrm{f}_{7 / 2}\right)$ in $\mathrm{Au}^{0}$ electronic state (Au nanoparticles). ${ }^{39}$ After annealing, the $\mathrm{Au} 4 \mathrm{f}_{5 / 2}$ peak appears as a shoulder of the $\mathrm{Zn} 3 \mathrm{p}_{3 / 2}$ peak also observed by Cheng et al. on Au-Zn alloys. ${ }^{40}$ These XPS analyses are consistent with a grafting of the Au NPs on the $\mathrm{ZnO}$ layer. After rinsing the annealed NPs on the substrate with DI water $(50 \mathrm{~mL}$ by $\mathrm{cm}^{2}$ ), all NPs remains on the surface (Figure $2 \mathrm{~b}$ ). Additional XPS spectra are given in the Supplementary Information file Figure S3.

The HRTEM cross-sections (Figure 1 e, f and Figure S4 in the Supplementary Information file) surprisingly show that the $\mathrm{Au}$ NPs are mostly incorporated inside the $\mathrm{ZnO}$ layer, independently of the annealing process, with $~ 98 \%$ of the Au NPs barely protruding above the $\mathrm{ZnO}$ surface. Compared to the two other investigated methods: SC and DPU (results are detailed in Supplementary Information SI-3 and 4), the P-D technique allows to covalently graft $\mathrm{Au}$ NPs on ZnO, yielding the highest NPs areal density with an average size below 10 nm.

Three main step of the P-D process determine the NPs growth, arrangement and chemical attachment with the surface during P-D process: 1) the nucleation/growth of $\mathrm{Au}$ on $\mathrm{ZnO} ; 2$ ) the localization of the nuclei in the confined spaces of the metal oxide film microstructure; and 3) the chemical interaction between the $\mathrm{ZnO}$ surface and $\mathrm{Au}$ NPs (after annealing at $\left.200^{\circ} \mathrm{C}\right)$. In the following part, we examine all these parameters in detail. 


\section{Sacrificial and stabilizing agent influence on nanoparticle nucleation and growth}

For in-situ processes, nucleation and growth are derived from the complex interplay between precusor-ligand and specific surface sites to generate nanoparticle seeds. Two mechanisms are usually invoked to describe the formation of metal or metal oxide nanoparticles from the reduction of a metal precursor: the LaMer mechanism (supersaturation of monomer in solution, nucleation and growth) and the Ostwald-Ripening mechanism (large particle grow at the expense of smaller particles). ${ }^{41}$ However, these classical processes are not well adapted to describe the photo-reduction method. In 2016, Harada et al. brought new considerations to understand the photo-generation process by distinguishing three sequential solution mechanisms during the formation of $\mathrm{Au} \mathrm{NPs}$ in a $\mathrm{HAuCl}_{4}$ salt solution, stabilized by a polyvinylpyrrolidone (PVP) polymer. ${ }^{42}$

a/

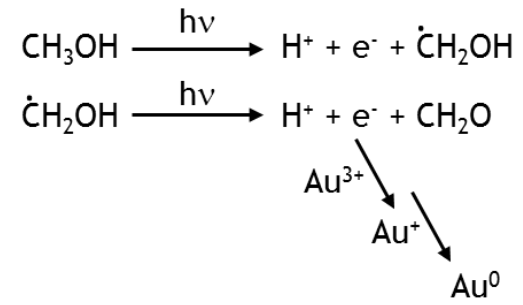

$\mathrm{b} /$

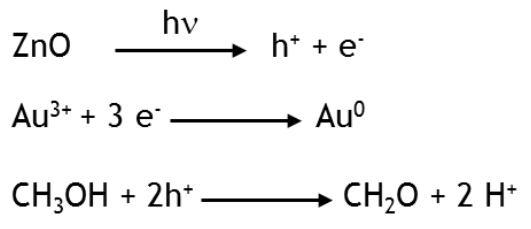

Scheme 1. Homogeneous (a) and heterogeneous (b) photo-reduction mechanism of Au(III) ions promoted by methanol.

The first step is rapid and consists in the reduction of $\mathrm{Au}^{3+}$ to $\mathrm{Au}^{+}$by alcohol radicals (Scheme 1 a).

The second step is the Au NP nucleation, including both autocatalytic and aggregative growth processes, yielding NPs with $\sim 15-30 \mathrm{~nm}$ diameter, stabilized by either the PVP or a polyvinyl alcohol (PVA). ${ }^{42,}$ In our case, we have chosen to use citrate stabilizers, as they may be better ligands than polymers in order to get smaller nanoparticles $(5-10 \mathrm{~nm})$. We 
found that the best $[$ citrate $] /\left[\mathrm{HAuCl}_{4}\right]$ ratio to get the highest numbers of particles seeds is around 20 (Figure 1). At room temperature, 95\% of NPs have a diameter below $10 \mathrm{~nm}$ at the end of the process.

The stages of nucleation and nanoparticle stabilization in the liquid phase are crucial to master homogeneous deposition of NPs on a substrate (packing density, shape and particle size homogeneity). For example, in P-D process, methanol plays the role of a sacrificial agent protecting the $\mathrm{ZnO}$ materials against the photo-corrosion phenomenon. ${ }^{29,42,44}$ If the process is performed without methanol, it results in citrate-stabilized Au NPs of $\sim 6.7 \pm 2 \mathrm{~nm}$ diameter, but their areal density is decreased to $1230 \pm 5 \mathrm{NPs} / \mu \mathrm{m}^{2}$, i.e. one fifth of the density obtained with optimized parameters (See SEM images in Figure S5 a). Furthermore, when P-D is performed without both sacrificial and stabilizing agents, NPs are polymorphic (spherical, triangular, nanorods ...) and present a high polydispersity ( $\sim 15-70 \mathrm{~nm}$ diam.) reflecting poor control of the nucleation and growth steps. In addition, a very low density of NPs is observed on the surface $\left(62 \pm 2 \mathrm{NPs} / \mathrm{mm}^{2}\right)($ See SEM images in Figure S5 b). Replacing citrate by PVA results in highly agglomerated 3-dimensional and inhomogeneous structures (Figure S5 c).

The third step is the aggregative growth and/or interparticle coalescence during the long photoirradiation stage, which typically lasts a few hours. During the deposition on a $\mathrm{ZnO}$ substrate, a competitive growth mechanism takes place upon irradiation, involving heterogeneous nucleation directly at the surface thanks to electron/holes pairs generated at $\mathrm{ZnO}$ surface, in parallel with the homogeneous nucleation mechanism occurring in solution (Scheme 1 b). ${ }^{29,42}$ Consequently, the reduction of the gold salt by electron/holes pairs is more suitable than the homogeneous nucleation mechanism to covalently bind $\mathrm{Zn}$ and $\mathrm{Au}$ atoms resulting in an attachment of the heterogeneous $\mathrm{Au}$ nuclei on the $\mathrm{ZnO}$ surface. Only a heterogeneous NP density of $18 \pm 3 \mathrm{NPs} / \mu^{2}$ is grafted on the $\mathrm{ZnO}$ surface during the P-D process (Figure 2 a). Here, the major part of the Au nuclei is likely created by a homogeneous 
nucleation mechanism since a typical purple solution of Au NPs is observed after the P-D process. The homogeneous nucleation mechanism leads to Au NPs stabilization by citrate ligands that are not initially grafted on the metal oxide film. A further annealing is required to completely graft the homogeneously nucleated Au NPs (Figure 1).

\section{Nuclei growth in confined space and role of surface morphology}

The main driving force for the growth of Au nanoparticles in confined spaces is the chemical interaction between the metal oxide film microstructure and the nanoparticle seeds. Our results suggest, however, that beyond these chemical mechanisms, the surface morphology may also play a crucial role in NP density and spatial distribution. Analysis of the STEM-EDS pictures in Figure $1 \mathrm{e}, \mathrm{f}$ shows the incorporation of Au NPs inside the $25 \mathrm{~nm}$ thick $\mathrm{ZnO}$ film; some NPs are even in intimate contact with the $\mathrm{ZnO}$ /oxidized Si interface (i.e. flattening of the nanoparticle surface in contact to the interface). Since the $\mathrm{ZnO}$ film is intrinsically rough due to its columnar growth, we postulate that the Au NPs nucleate at both grains boundaries and bottom of the valleys separating grains. This hypothesis is supported by the fact that the diameter of Au NPs $(7.5 \pm 3 \mathrm{~nm}$ in diameter $)$ is similar to the valleys that separate the two populations of $\mathrm{ZnO}$ grains characterized by different grain sizes $(9.2 \pm 0.4$ $\mathrm{nm}$ and $15.4 \pm 2 \mathrm{~nm}$ ). Indeed, the structurally diverse $\mathrm{ZnO}$ environment inside the valleys can favor the initial nucleation (seeding) and subsequent growth of NPs inside the ZnO grains forest. Consequently, the NP seeds are already deeply located inside the thin $\mathrm{ZnO}$ film (i.e. in the valleys) before annealing (Figure $1 \mathrm{e}$ ). The effect of annealing allows to strengthen the interfaces between $\mathrm{ZnO}$ and $\mathrm{Au}$, which will be discussed in the next section below. Thus, the precise location inside the film and resulting integration are achieved in one single step $(\sim 30$ min), which is important for most technological applications. 
In order to quantitatively confirm the previous finding, the same processing conditions were used for the P-D onto a much thicker $(128 \mathrm{~nm}) \mathrm{ZnO}$ film grown by ALD. The HRTEM pictures in Figure 3 a show that there is a lower density region in the $\mathrm{ZnO}$ film (lighter; 20 $\mathrm{nm}$ in depth) and that the Au NPs are located inside this region, without penetration into the denser (darker) part of the film. In Figure $3 \mathrm{~b}$, the STEM-EDS analyses performed along the red line show a loss of zinc in the top $20 \mathrm{~nm}$ of the $\mathrm{ZnO}$ film, due mostly to the presence of the $\mathrm{Au}$ NPs and to a lesser extend the lower density of the $\mathrm{ZnO}$ in this region. This experiment provides evidence for the limited penetration of $\mathrm{Au}$ within the $\mathrm{ZnO}$ grains (Figure 3). The growth of the Au NPs in confined spaces is commensurate with the larger width of the $\mathrm{ZnO}$ columns $(20 \pm 5 \mathrm{~nm})$ in these thicker films (Figure S6, S7), compared to those of the 25nmthick ZnO films (9 to $15 \mathrm{~nm}$; see Figure S1). Moreover, on the $128 \mathrm{~nm}$ thick ZnO, the Au NPs exhibit an average size of $13 \pm 3 \mathrm{~nm}$ with a lower NPs areal density of $2000 \pm 20 \mathrm{NPs} / \mu^{2}$ compared to $7.5 \pm 3 \mathrm{~nm}$ and $3500 \pm 10 \mathrm{NPs} / \mu \mathrm{m}^{2}$ obtained on the $25 \mathrm{~nm}$-thick $\mathrm{ZnO}$, respectively. These results suggest that the size and arrangement of the $\mathrm{ZnO}$ grains at the surface of the film controls the size and location of the Au NPs. Tuning the ZnO surface morphology can therefore significantly improve the Au NPs nucleation rate and growth process. Finally, the metal oxide grains size greatly influences the size of the confined spaces (i.e. the valleys) between the random metal oxide grains distribution. These resulting confined spaces lead the growth of the Au nuclei with a limitation on the Au nanoparticles size directly depending on the size of the valleys. The Au NPs stabilized by citrate are localized inside the $\mathrm{ZnO}$ grain structure (Figure 3). 

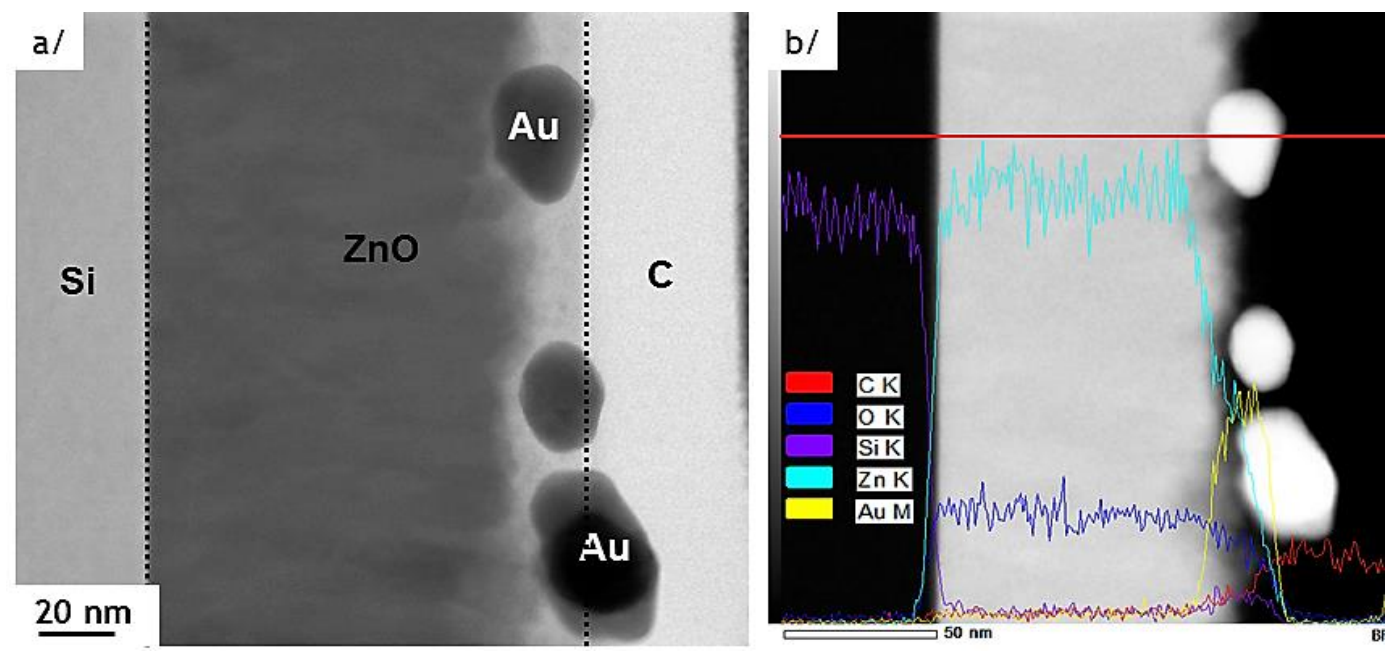

Figure 3. HRTEM observation (a) and STEM-EDS analyses along the red horizontal red line showing the quantity of each element: $\mathrm{C}, \mathrm{O}, \mathrm{Si}, \mathrm{Zn}, \mathrm{Au}$ as a function of the position on the red line (b) for the lamella of the sample $\mathrm{Au} / \mathrm{ZnO} 128$.

\section{Characterization of Au NPs bonding to $\mathrm{ZnO}$}

As previously mentioned, the quality of the $\mathrm{Au} / \mathrm{ZnO}$ interface is necessary to obtain best physico-chemical properties (plasmonic, catalysis, ...). Thermal annealing is currently used to remove stabilizing organic ligands surrounding the nanoparticles and thus obtain a chemical bonding to the metal oxide. ${ }^{45}$ However, annealing may also modify the Au NP size and/or shape and/or interfacial composition of the nanoparticles since Au atoms are mobile even at relatively modest temperatures. A relatively low annealing process $\left(200{ }^{\circ} \mathrm{C}, 2 \mathrm{~h}\right.$, air $)$ fosters covalent grafting of the Au NPs on the surface with no significant modification of their average size (from $7.5 \pm 3$ to $8.3 \pm 2 \mathrm{~nm}$ ) and shape on $25 \mathrm{~nm} \mathrm{ZnO}$ films (Figure $1 \mathrm{a}$, b, Figure $2 \mathrm{~b})$. In fact, there is no detectable change of the $\mathrm{Zn} 3 \mathrm{p}_{3 / 2}$ and $\mathrm{Au} 4 \mathrm{f}_{5 / 2}$ binding energies $(\Delta \mathrm{E}=$ $1.7 \mathrm{eV}$ ), which occurs in Au-Zn alloys. ${ }^{46}$ However, this covalent contact between the Au NPs and $\mathrm{ZnO}$ does foster some elemental intermixing, i.e. formation of $\mathrm{Au}-\mathrm{Zn}$ bonds at the $\mathrm{Au} / \mathrm{ZnO}$ interface. To examine this possibility, we use the reported characteristics of pure Au$\mathrm{Zn}$ alloys: the $\mathrm{Au} 4 \mathrm{f}_{5 / 2}$ disappears due to its blue-shift and merges with the $\mathrm{Zn} 3 \mathrm{p}_{3 / 2}$ peak, leaving only the $\mathrm{Au} 4 \mathrm{f}_{7 / 2}$ peak. $^{40}$ In our case, the intensity of the $\mathrm{Au} 4 \mathrm{f}_{5 / 2}$ peak in the annealed 
sample is slightly reduced relative to the $4 \mathrm{f}_{7 / 2}$ peak but remains as a shoulder of the $\mathrm{Zn} 3 \mathrm{p}_{3 / 2}$ peak (Figure $1 \mathrm{~d}$ ). The presence of this shoulder suggests that only a limited number of $\mathrm{Zn}$ atoms are covalently bound to Au. Same results are obtained for Au NPs on 128 nm-thick ZnO films (Figure S8). The above observations suggest the formation of a limited fraction of an interfacial $\mathrm{Au}-\mathrm{Zn}$ alloy between $\mathrm{Au}$ NPs and $\mathrm{ZnO}$ film.

Moreover, a vigorous rinsing cannot remove the Au NPs after the annealing step (Figure 2 b) which supports the possible covalent interaction between $\mathrm{Au}$ and $\mathrm{ZnO}$.

XPS is also useful to determine whether carbon contamination is present in the $\mathrm{Au}$ $\mathrm{NP} / \mathrm{ZnO}$ system from citrates after processing. The ratio $\mathrm{C} 1 \mathrm{~s} / \mathrm{Zn} 2 \mathrm{p}_{1 / 2,3 / 2}$ decreases from 1.24 to 0.04 after the annealing and the rinsing step confirming that most citrate ligands are removed by this method.

In summary, the annealing process achieves covalent grafting of Au NPs on $\mathrm{ZnO}$ and is gentle enough to maintain the shape, size and location of the Au NPs. A final deionized water rinsing step ensures the removal of the majority of the citrate ligands surrounding the Au NPs in order to clean the surface and to obtain ultra-pure $\mathrm{Au} / \mathrm{ZnO}$ interfaces, which is critical for many applications.

\section{Comparison of P-D process with other conventional NPs deposition methods}

As presented in the Introduction, spin coating and deposition precipitation with urea were also tested for grafting Au NPs on $\mathrm{ZnO}$ surfaces. Details are presented in sections 3 and 4 of the Supplementary Information. A summary of the Au NPs average size and areal density obtained for each methods is given in Table 1 for specific post-processing conditions, thus providing a comparison with results obtained by the P-D method. 
Table 1. Au NPs average size and areal density as a function of post-processing conditions for the three studied methods: P-D, SC and DPU.

\begin{tabular}{|c|c|c|c|c|c|}
\hline Sample & Process & $\begin{array}{c}\text { ZnO film } \\
\text { thickness (nm) }\end{array}$ & $\begin{array}{l}\text { post-processing } \\
\text { conditions }\end{array}$ & $\begin{array}{l}\text { Au NPs average } \\
\text { size }(\mathrm{nm})\end{array}$ & $\begin{array}{c}\text { Au NPs areal } \\
\text { density } \\
\left(\mathrm{NPs} / \mu \mathrm{m}^{2}\right)\end{array}$ \\
\hline $\mathrm{Au} / \mathrm{ZnO} 25$ & & & & $7.5 \pm 3$ & $3500 \pm 10$ \\
\hline $\mathrm{Au} / \mathrm{ZnO} 25$ & & 25 & rinsed & - & $18 \pm 3$ \\
\hline $\mathrm{Au} / \mathrm{ZnO} 25 \_200^{\circ} \mathrm{C}$ & $P-D$ & & annealed + rinsed & $8.3 \pm 2$ & $3700 \pm 10$ \\
\hline $\mathrm{Au} / \mathrm{ZnO} 128$ & & & & $13 \pm 3$ & $2000 \pm 20$ \\
\hline $\mathrm{Au} / \mathrm{ZnO} 128$ low density & & 128 & rinsed & $31 \pm 8$ & $16 \pm 1$ \\
\hline $\mathrm{Au} / \mathrm{ZnO} 0128 \_200^{\circ} \mathrm{C}$ high density & & & annealed + rinsed & $13 \pm 3$ & $2000 \pm 20$ \\
\hline $\mathrm{Au} / \mathrm{ZnO} 25$ & SC & 25 & & $8.2 \pm 0.9$ & $60 \pm 3$ \\
\hline $\mathrm{Au} / \mathrm{ZnO} 25$ & DPU & 20 & annealed & $5.4 \pm 2 ; 14.5 \pm 4$ & $950 \pm 10$ \\
\hline
\end{tabular}

Pre-synthesized Au NPs stabilized by citrate ligands can effectively be spin coated on the ZnO film. Despite a high-control on the Au NPs size (Figure S9, Table S2), a very low density of NPs is deposited: $\sim 60 \pm 3 \mathrm{NPs} / \mu_{\mathrm{m}}^{2}$ at $6000 \mathrm{rpm}$ (Figure S10, Table 1).

The DPU process leads to the formation of two populations of $\mathrm{Au}$ NPs on $\mathrm{ZnO}$ surface: $\sim 30 \%$ of the NPs are $5.4 \pm 2 \mathrm{~nm}$ in diameter and $\sim 70 \%$ are $14.5 \pm 4 \mathrm{~nm}$ in diameter. The $\mathrm{Au}$ NPs areal density is $950 \pm 10 \mathrm{NPs} / \mu \mathrm{m}^{2}$. However, we observed that the too high concentration of the acidic gold precursor $\mathrm{HAuCl}_{4}$ leads to a dissolution of the $\mathrm{ZnO}$ layer leading to the complete vanishing of ZnO. Figure S11 shows Au NPs grafted on the native silicon oxide layer instead of $\mathrm{ZnO}$.

In summary, only the P-D process permits to graft uniformally high densities (> 2000 $\mathrm{NPs} / \mu \mathrm{m}^{2}$ ), clean and size controlled Au NPs on $\mathrm{ZnO}$ thin films thanks to the quick generation of a great number of Au nuclei. In addition, the insertion of Au NPs within the thin $\mathrm{ZnO}$ layer leads to a high quality grafting (high stability). Finally, we demonstrate that the postprocessing step permits to control the zinc oxide microstructure (Figure S6, Figure S7 and Table 1) and/or the final Au NPs areal density. 


\section{Photocatalytic performance of $\mathrm{P}-\mathrm{D} \mathrm{Au} / \mathrm{ZnO}$ materials in the photo-degradation of}

\section{Rhodamine 6G and in the photo-reduction of water.}

In order to demonstrate the potential interest of $\mathrm{Au} / \mathrm{ZnO}$ materials for photocatalytic applications, two different photocatalytic reactions were studied. First, the photo-degradation of a prototypical organic contaminant (Rhodamine 6G) was explored using a $128 \mathrm{~nm}$ thick $\mathrm{ZnO}$ film decorated with a high density of Au NPs $\left(2000 \pm 20 \mathrm{NPs} / \mu^{2}{ }^{2}\right)$ under UV-vis irradiation (UV Rayonet ${ }^{\circledR}$ system composed by 16 lamps $\lambda=253.7$ (4 lamps), 300 (4 lamps), 350 (4 lamps) and $575 \mathrm{~nm}$ (4 lamps), 224 Watts). Figure 4 a shows that the presence of $\mathrm{Au}$ on $\mathrm{ZnO}$ film enhances the photo-degradation process. The photocatalytic degradation of dyes $^{47,} 48$ is let possible by the reaction between the photo-induced holes during the photocatalysis and $-\mathrm{OH}$ species and the dye leads to the degradation of this latter. After $7 \mathrm{~h}$, $\sim 70 \%$ of the Rhodamine $6 \mathrm{G}$ is photo-degraded when Au NPs are grafted on ZnO compared to only $\sim 50 \%$ without NPs. In a second experiment, the photo-reduction of water was studied in a water-ethanol solution (50-50) under UV-vis irradiation (Xenon, 300 Watts). Figure $4 \mathrm{~b}$ shows that only the $\mathrm{ZnO}$ with $\mathrm{Au}$ NPs produces a measurable photocatalytic yield for the reduction of water, as the photo-catalytic activity is close to zero for the bare $128 \mathrm{~nm}$-thick $\mathrm{ZnO}$ film. 

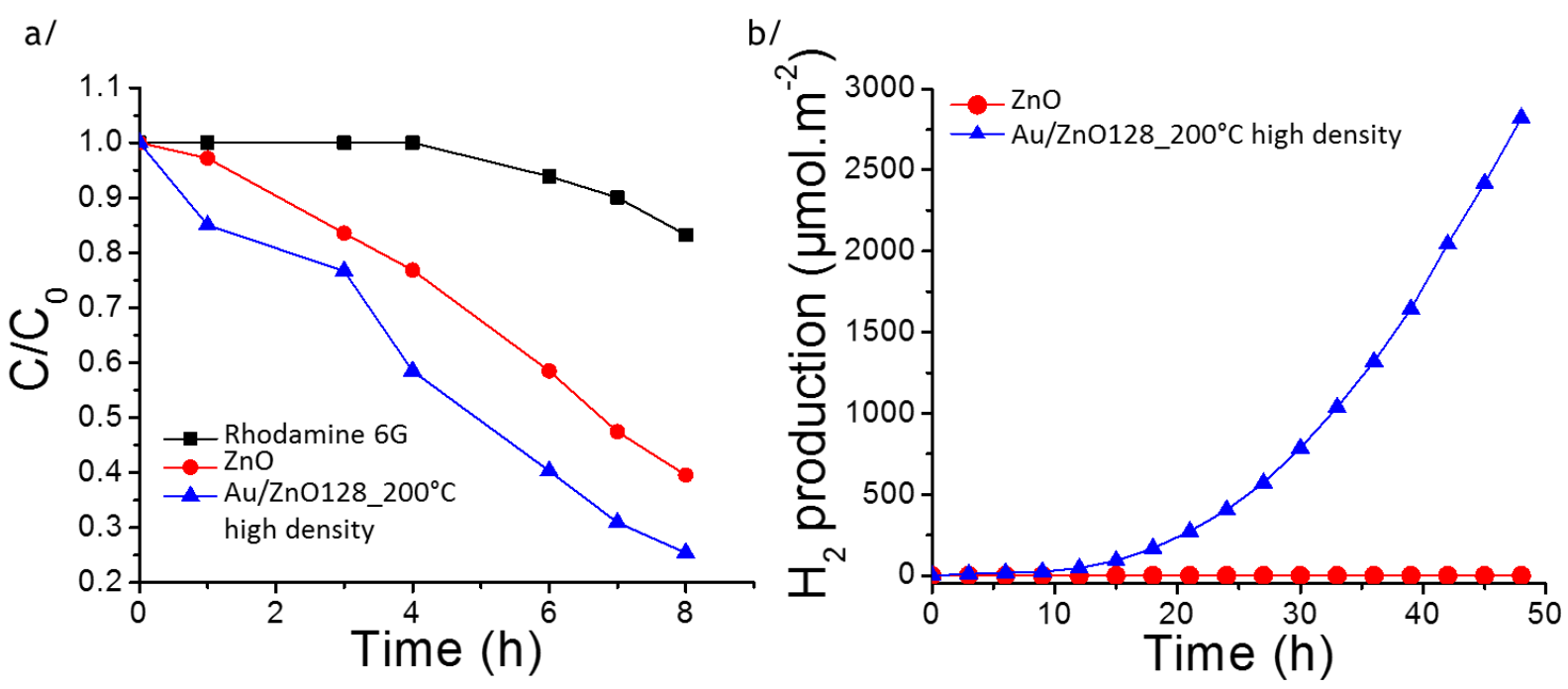

Figure 4. Photo-degradation of Rhodamine 6G (a) and production of $\mathrm{H}_{2}$ from the photoreduction of water (b) under UV-vis irradiation $(\lambda=250-800 \mathrm{~nm})$. Controlled experiment of Rhodamine 6G photobleaching (black, square), $128 \mathrm{~nm} \mathrm{ZnO}$ film (red, circle), $128 \mathrm{~nm} \mathrm{ZnO}$ film covered with a high density of grafted Au NPs $\left(2000 \pm 20 \mathrm{NPs} / \mu \mathrm{m}^{2}\right)$ (blue, triangle up).

Typically, the photons induce electron-hole pairs in the semiconducting metal oxide film; these electrons reduce the $\mathrm{H}_{2} \mathrm{O}$ into $\mathrm{H}_{2}$ and the holes oxidize the sacrificial molecules (ethanol in our case). Due to their plasmonic properties, the gold nanoparticles extend the light absorption to the visible region (see UV-vis spectra of $\mathrm{ZnO}$ film covered with a high density of $\mathrm{Au}$ NPs in Supplementary File SI-5 and Figure S14) and thus play the role of a photosensitizer resulting in an increase of the photocatalytic activity. ${ }^{49,} 50$ The unique feature here is that the $\mathrm{Au}$ NPs are grafted within the $\mathrm{ZnO}$ structure without organic ligands, thus enhancing the interaction between their LSPR field and the semiconducting ZnO film. The possibility to graft a high density (up to $2000 \pm 20 \mathrm{NPs} / \mu \mathrm{m}^{2}$ ) of $\mathrm{Au}$ NPs within the $\mathrm{ZnO}$ structure increases the $\mathrm{ZnO}$ regions strongly affected by the plasmonic field, which contributes in enhancing the water photo-reduction yield. 


\section{Conclusion}

In this work, the deposition of Au NPs on $\mathrm{ZnO}$ films was explored in order to achieve low NP size and homogeneous shape, high areal density, high purity and good chemical grafting with the metal oxide film. Among three possible methods to deposit Au NPs on $\mathrm{ZnO}$-spin coating, deposition precipitation with urea and photo-deposition (P-D) only P-D achieved good enough results to be useful for most applications. The modified P-D technique developed herein and using citrate ligands instead of usual polymer ones, produces homogeneously and covalently grafted spherical Au NPs $(7.5 \pm 3 \mathrm{~nm}$ in diam.) with a high packing density of $\sim 3600 \mathrm{NPs} / \mu \mathrm{m}^{2}$ (1/3 of the maximal theoretical packing density). The high density of $\mathrm{Au}$ NPs has a direct impact on the activity of photocatalytic reactions. We demonstrate that high densities of Au NPs embedded within $\mathrm{ZnO}$ film enhance the production of hydrogen by photo-reduction of water and the photo-degradation of Rhodamine 6G. Furthermore, most of the Au NPs are intercalated into the $25 \mathrm{~nm} \mathrm{ZnO} \mathrm{layer} \mathrm{with} \mathrm{only} ~ 1 / 5$ of their volume emerging out of the metal oxide layer. A soft annealing at $200{ }^{\circ} \mathrm{C}$ under air and simple rinse with water ensures a good chemical purity and efficient carbon removal from the film.

While the confinement of nano-objects in small volume remains a great challenge in nanotechnologies in general, the photo-deposition process is able to covalently graft Au NPs on $\mathrm{ZnO}$ thin films. The compatibility with large area grafting and the low carbon contamination of the photo-deposition process makes it of great interest for many applications needing high purity materials such as photovoltaics, photocatalysis, water purification or biosensors. 


\section{Supporting Information}

XRD and XPS characterizations of the ZnO films; SEM observations and XPS characterizations of the samples realized by spin coating, Precipitation/deposition with urea and photo-deposition. This material is available free of charge via the Internet at http://pubs.acs.org.

\section{Corresponding Author}

*E-mail: jcure@laas.fr and rossi@laas.fr

\section{Notes}

The authors declare no competing financial interest.

\section{Acknowledgment}

The authors would like to thank the French Technological Network RENATECH having partially funded the ALD deposition equipment and the University of Toulouse for the financial support of the Project MUSE (chaire d'attractivité). The authors also acknowledge Jerôme Esvan from the CIRIMAT for the XPS analyses, Teresa Hungria from "Plateforme de caractérisation Raymond Castaing" for the HRTEM observations, and Benjamin Reig from LAAS for the preparation of the lamella.

\section{References}

1. Yang, Y.; Huang, J.; Yang, X.; Quan, K.; Wang, H.; Ying, L.; Xie, N.; Ou, M.; Wang, K., Aptazyme-Gold Nanoparticle Sensor for Amplified Molecular Probing in Living Cells. Anal. Chem. 2016, 88, 5981-5987.

2. $\mathrm{Hu}$, J.; You, N.; Yu, Z.; Zhou, G.; Xu, X., Two-dimensional ZnO ultrathin nanosheets decorated with $\mathrm{Au}$ nanoparticles for effective photocatalysis. J. Appl. Phys. 2016, 120, 074301/1-074301/8. 
3. Xia, W.; Mei, C.; Zeng, X.; Fan, G.; Lu, J.; Meng, X.; Shen, X., Nanoplate-Built ZnO Hollow Microspheres Decorated with Gold Nanoparticles and Their Enhanced Photocatalytic and Gas-Sensing Properties. ACS Appl. Mater. Interfaces 2015, 7, 11824-11832.

4. Sartorio, C.; Scaramuzza, S.; Cataldo, S.; Vetri, V.; Scorpelliti, M.; Leone, M.; Amendola, V.; Pignataro, B., Donnor-Acceptor Interfaces by Engineered Nanoparticles Assemblies for Enhanced Efficiency in Plastic Planar Heterojunction Solar Cells. J. Phys Chem. 2016, 120, 26588-26599.

5. $\quad$ Nakamura, K.; Oshikiri, T.; Ueno, K.; Wang, Y.; Kamata, Y.; Kotake, Y.; Misawa, H., Properties of Plasmon-Induced Photoelectric Conversion on a TiO2/NiO p-n Junction with Au Nanoparticles. J. Phys. Chem. Lett. 2016, 7, 1004-1009.

6. Garg, V.; Sengar, B. S.; Awasthi, V.; Aaryashree; Sharma, P.; Mukherjee, C.; Kumar, S.; Mukherjee, S., Localized surface plasmon resonance on $\mathrm{Au}$ nanoparticles: tuning and exploitation for performance enhancement in ultrathin photovoltaics. RSC Adv . 2016, 6, 26216-26226.

7. Li, X.; Xiong, Z.; Xu, X.; Luo, Y.; Peng, C.; Shen, M.; Shi, X., 99mTc-Labeled Multifunctional Low-Generation Dendrimer-Entrapped Gold Nanoparticles for Targeted SPECT/CT Dual-Mode Imaging of Tumors. ACS Appl. Mater. Interfaces 2016, 8, 1988319891.

8. Snegir, S.; Mukha, I.; Sysoiev, D.; Lacaze, E.; Huhn, T.; Pluchery, O., Optically controlled properties of nanoparticles stabilised by photochromic difurylethene-base diarylethenes. Materialwissenschaft und Werkstofftechnik 2016, 47, 229-236.

9. Pluchery, O.; Humbert, C.; Valamanesh, M.; Lacaze, E.; Busson, B., Enhanced detection of tiophenol adsorbed on gold nanoparticles by SFG and DFG nonlinear optical spectroscopy. Phys Chem Chem Phys 2009, 11, 7729-7737.

10. Banerjee, A.; Scott, R. W. J., book chapter in Nanocatalysis in Ionic Liquids by Martin Prechtl. Wiley-VCH 2016, Ch. 6 (pp 97-123), "Au, Ag and Cu Nanostructures".

11. Ji, X.; Song, X.; Li, J.; Bai, Y.; Yang, W.; Peng, X., Size Control of Gold Nanocrystals in Citrate Reduction: The Third role of Citrate. J. Am. Chem. Soc. 2007, 129, 13939-13948.

12. Al-Johani, H.; Abou-Hamad, E.; Jedidi, A.; Widdifield, C. M.; Viger-Gravel, J.; Sangaru, S. S.; Gajan, D.; Anjum, D. H.; Ould-Chikh, S.; Hedhili, M. N.; Gurinov, A.; Kelly, M. J.; El Ester, M.; Cavallo, L.; Emsley, L.; Basset, J.-M., The structure and binding mode of citrate in the stabilization of gold nanoparticles. Nat. Chem. 2017.

13. Li, Z.; Gao, F.; Gu, Z., Vertically aligned Pt nanowire array/Au nanoparticle hybrid structure as highly sensitive amperometric biosensors. Sens. Actuators B 2017, 243, 10921101.

14. Farcau, C.; Sangeetha, N. M.; Moreira, H.; Viallet, B.; Grisolia, J.; CiuculescuPradines, D.; Ressier, L., High-Sensitivity strain gauge based on a single wire of gold nanoparticles fabricated by stop-and-go convective self-assembly. ACS Nano 2011, 5, 71377143.

15. Yu, Y.; Wen, W.; Qian, X.-Y.; Liu, J.-B.; Wu, J.-M., UV and visible light photocatalytic activity of $\mathrm{Au} / \mathrm{TiO} 2$ nanoforests with Anatase/Rutile phase junctions and controlled Au locations. Sci. Rep. 2017, 7, 41253.

16. Koh, S. J., Strategies for controlled placement of nanoscale building blocks. Nanoscale Res. Lett. 2007, 2, 519-545.

17. Shen, S. C.; Wen-Tao, L.; Jia-Jie, D., Colloidally deposited nanoparticle wires for biophysical detection. Chin. Phys. B 2015, 24, 127308.

18. Stetsenko, M. O.; Rudenko, S. P.; Maksimenko, L. S.; Serdega, B. K.; Pluchery, O.; Snegir, S. V., Optical Properties of Gold Nanoparticles Assemblies on a Glass Surface. Nanoscale Res. Lett. 2017, 12, 348. 
19. Schlichthaerle, T.; Strauss, M. T.; Schueder, F.; Woehrstein, J. B.; Jungmann, R., DNA nanotechnology and fluorescence applications. Curr. Opin. Biotechnol. 2016, 39, 41-47. 20. Michel, R.; Reviakine, I.; Sutherland, D.; Fokas, C.; Csucs, G.; Danuser, G.; Spencer, N. D.; Textor, M., A Novel Approach To Produce Biologically Relevant Chemical Patterns at the Nanometer Scale: Selective Molecular Assembly Patterning Combined with Colloidal Lithography. Langmuir 2002, 18, 8580-8586.

21. Leggett, G. J., Direct writting of metal nanostructures: lithographic tools for nanoplasmonics research. ACS Nano 2011, 5, 1575-1579.

22. Spatz, J. P.; Mossmer, S.; Hartmann, C.; Moller, M.; Herzog, T.; Krieger, M.; Boyen, H.-G.; Ziemann, P.; Kabius, B., Ordered Deposition of Inorganic Clusters from Micellar Block Copolymer Films. Langmuir 2000, 16, 407-415.

23. Chen, H. M.; Chen, C. K.; Chen, C.-J.; Cheng, L.-C.; Wu, P. C.; Cheng, B. H.; Ho, Y. Z.; Tseng, M. L.; Hsu, Y.-Y.; Chan, T.-S.; Lee, J.-F.; Liu, R.-S.; Tsai, D. P., Plasmon Inducing Effects for Enhanced Photoelectrochemical Water Splitting: X-ray Absorption Approach to Electronic Structures. ACS Nano 2012, 6, 7362-7372.

24. Reineck, P.; Brick, D.; Mulvaney, P.; Bach, U., Plasmonic Hot Electron Solar Cells: The Effect of Nanoparticle Size on Quantum Efficiency. J. Phys. Chem. Lett. 2016, 7, 41374141.

25. Wu, F.; Tian, L.; Kanjolia, R.; Singamaneni, S.; Banerjee, P., Plasmonic Metal-toSemiconductor Switching in Au Nanorod-ZnO nanocomposite films. ACS Appl. Mater. Interfaces 2013, 5 (16), 7693-7697.

26. Shivhare, A.; Scott, R. W. J., Following the thermal and chemical activation of supported Au clusters using X-ray absorption spectroscopy. RSC Adv. 2016, 6 (67), 6257962584.

27. Sharma, V. K.; Filip, J.; Zboril, R.; Varma, R. S., Natural inorganic nanoparticles formation, fate, and toxicity in the environment. Chem. Soc. Rev. 2015, 44, 8410-8423.

28. Gao, Z.; Wu, F.; Myung, Y.; Fei, R.; Kanjolia, R.; Yang, L.; Banerjee, P., Standing and sitting adlayers in atomic layer deposition of ZnO. J. Vac. Sci. Technol. A 2016, 34 (1), 01A143/1-01A143/10.

29. Liu, Y.; Gu, Y.; Yan, X.; Kang, Z.; Lu, S.; Sun, Y.; Zhang, Y., Design of sandwichstructured $\mathrm{ZnO} / \mathrm{ZnS} / \mathrm{Au}$ photoanode for enhanced efficiency of photoelectrochemical water splitting. Nano Research 2015, 8, 2891-2900.

30. Pucci, A.; Bernabo, M.; Elvati, P.; Itzel Meza, L.; Galembeck, F.; Alberto de Paula Leite, C.; Tirelli, N.; Ruggeri, G., Photoinduced formation of gold nanoparticles into vinyl alcohol based polymers. J. Mater. Chem. 2006, 16, 1058-1066.

31. Hu, L.; Pfirman, A.; Chumanov, G., Stabilization of $2 \mathrm{D}$ assemblies of silver nanoparticles by spin-coating polymers. Appl. Surf. Sci. 2015, 357, 1587-1592.

32. Jonca, J.; Ryzhikov, A.; Fajerwerg, K.; Kahn, M. L.; Chaudret, B.; Chapelle, A.; Menini, P.; Fau, P., A Novel SnO2 Sensor and its Selectivity Improvement with Catalytic Filter. Procedia Engineering 2014, 87, 923-926.

33. Zanella, R.; Delannoy, L.; Louis, C., Mechanism of deposition of gold precursors onto $\mathrm{TiO} 2$ during the preparation by cation adsorption and deposition-precipitation with $\mathrm{NaOH}$ and urea. Appl. Catal. A 2005, 291, 62-72.

34. Orros-Ruiz, S.; Zanella, R.; Lopez, R.; Hernandez-Gordillo, A.; Gomez, R., Photocatalytic hydrogen production by water/methanol decomposition using $\mathrm{Au} / \mathrm{TiO} 2$ prepared by deposition-precipitation with urea. J. Hazard. Mater. 2013, 263, 2-10.

35. Zanella, R.; Giorgio, S.; Henry, C. R.; Louis, C., Alternative Methods for the Preparation of Gold Nanoparticles Supported on TiO2. J. Phys. Chem. B 2002, 106, 76347642. 
36. Tran, N. D.; Besson, M.; Descorme, C.; Fajerwerg, K.; Louis, C., Influence of the pretreatment conditions on the performances of $\mathrm{CeO} 2$-supported gold catalysts in the catalytic wet air oxidation of carboxylic acids. Catal. Commun. 2011, 16, 98-102.

37. Shirley, D. A., High-resolution x-ray photoemission spectrum of the valence bands of gold. Phys. Rev. 1972, 5, 4709.

38. Rajan, A.; Yadav, H. K.; Gupta, V.; Tomar, M., Plasmonic enhancement of optical absorption of UV radiation by $\mathrm{Au}$ nanoparticles dispersed on $\mathrm{ZnO}$ thin film. Appl. Phys. A 2014, 116, 913-919.

39. Santhanalakshmi, J.; Manoj, D.; Kumar, D. R., Au-ZnO bullet-like heterodimer nanoparticles: synthesis and use for enhanced nonenzymatic electrochemical determination of glucose. $R S C A d v$. 2014, 4, 8943-8952.

40. Cheng, Y.; Lu, S.; Xu, W.; Wen, H.; Wang, J., Fabrication of superhydrophobic Au$\mathrm{Zn}$ alloy surface on a zinc substrate for roll-down, self-cleaning and anti-corrosion properties. J. Mater. Chem. A 2015, 3, 16774-16784.

41. LaMer, V. K., Kinetics in phase transitions. Ind. Eng. Chem. 1952, 44, 1270-1277.

42. Harada, M.; Kizaki, S., Formation Mechanism of Gold Nanoparticles Synthesized by Photoreduction in Aqueous Ethanol Solutions of Polymers Using In Situ Quick Scanning Xray Absorption Fine Structure and Small-Angle X-ray Scattering. Cryst. Growth Des. 2016, $16,1200-1212$.

43. Liu, Y.; Yan, X.; Kang, Z.; Li, Y.; Shen, Y.; Sun, Y.; Wang, L.; Zhang, Y., Synergistic Effect of Surface Plasmonic particles and Surface Passivation layer on ZnO Nanorods Array for Improved Photoelectrochemical Water Splitting. Sci. Rep. 2016, 6, 29907.

44. Han, J.; Qiu, W.; Gao, W., Potential dissolution and photo-dissolution of $\mathrm{ZnO}$ thin films. J. Hazard. Mater. 2010, 178, 115-122.

45. Wang, T.; Jiao, Z.; Chen, T.; Li, Y.; Ren, W.; Lin, S.; Lu, G.; Ye, J.; Bi, Y., Vertically aligned $\mathrm{ZnO}$ nanowire arrays tip-grafted with silver nanoparticles for photoelectrochemical applications. Nanoscale 2013, 5, 7552-7557.

46. Thomas, T. D.; Weightman, P., Valence electronic structure of gold-zinc and goldmagnesium alloys derived from a new way of analyzing Auger-parameter shifts. Phys. Rev. $B$ 1986, 33, 5406-5413.

47. Panigrahy, B.; Sarma, D. D., Enhanced photocatalytic efficiency of AuPd nanoalloy decorated $\mathrm{ZnO}$-reduced graphene oxide nanocomposites. $R S C A d v$. 2015, 5, 8918-8928.

48. Manna, J.; Vinod, T. P.; Flomin, K.; Jelinek, R., Photocatalytic hybrid Au/ZnO nanoparticles assembled through a one-pot method. J. Colloid Interface Sci. 2015, 460, 113118.

49. Zhang, Z.; Choi, M.; Baek, M.; Deng, Z.; Yong, K., Corrosion-Assisted Self-Growth of Au-Decorated $\mathrm{ZnO}$ Corn Silks and Their Photoelectrochemical Enhancement. ACS Appl. Mater. Interfaces 2017, 9, 3967-3976.

50. Wu, M.; Chen, W.-J.; Shen, Y.-H.; Huang, F.-Z.; Li, C.-H.; Li, S.-K., In Situ Growth of Matchlike $\mathrm{ZnO} / \mathrm{Au}$ Plasmonic Heterostructure for Enhanced Photoelectrochemical Water Splitting. ACS Appl. Mater. Interfaces 2014, 6, 15052-15060. 


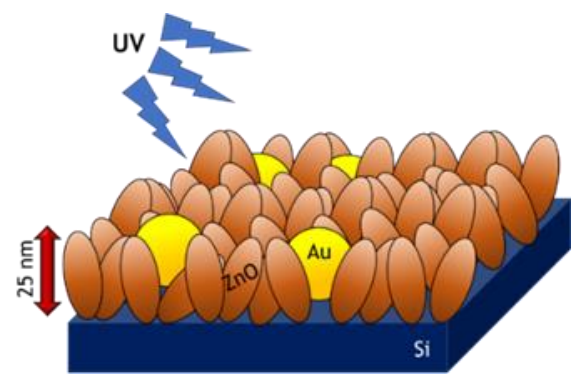

Table of Contents artwork. Intercalation of Au NPs inside $\mathrm{ZnO}$ thin film by PhotoDeposition. 